\title{
New Terpenoids from Amentotaxus formosana
}

Hui-Ling Chen, Li-Wen Wang, Huey-Jen Su, Bai-Luh Wei, Sheng-Zehn Yang, and Chun-Nan Lin *

School of Pharmacy, Kaohsiung Medical University, Kaohsiung 807, Taiwan Department of Nursing, Mei-Ho Institute of Technology, Pintung Hsien 912, Taiwan Institute of Life Science, National Taitung University, Taitung 950, Taiwan Department of Forest Resource, Management and Technology, National Pintung University of Science and Technology, Pintung Hsien 912, Taiwan

\section{List of Supporting Information:}

${ }^{1} \mathrm{H}$ NMR and ${ }^{13} \mathrm{C}$ NMR spectra of $\mathbf{1}$ 

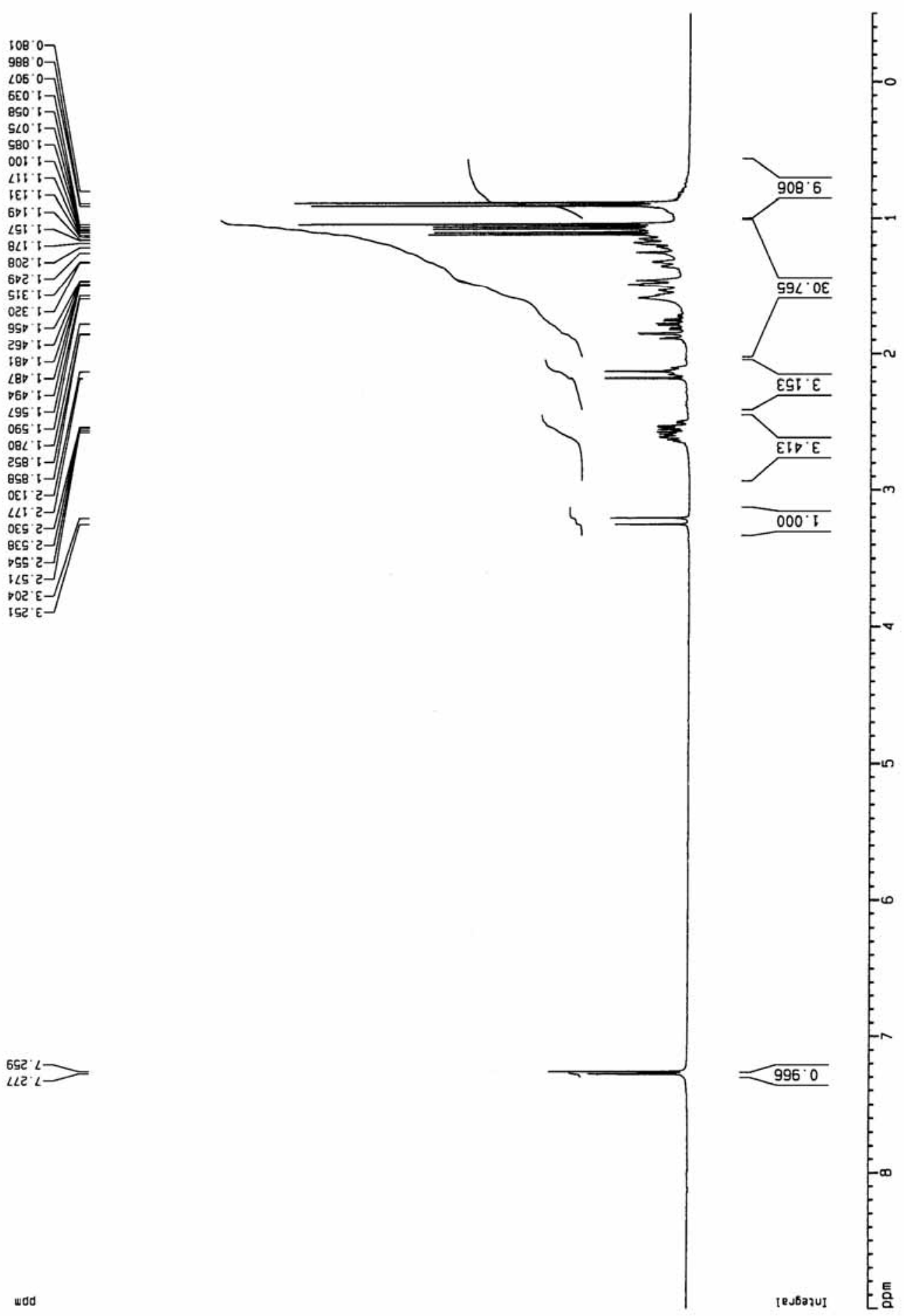
S6. $\angle L$
BEE $\triangle 1$

हE! ' 12

66E. 12

(96)

$\angle 06 \cdot \nabla 2$

c52. 28

เรQ. $\mathrm{CE}$

SEB. $E E$

$568^{\circ} \mathrm{LE}$

LEO' 6 E

086 . ED

EET $\angle V+$

$908^{\circ} \angle 9-$

$989.9 L$
$826.9 L$

200.

SOL' $L L$

ธเE. $U L$

995: $\angle L$

20E. $251-$
8IE. $251-$

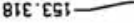

$162 \cdot 102-$
$1 / 2 L^{\circ} 802$

wod

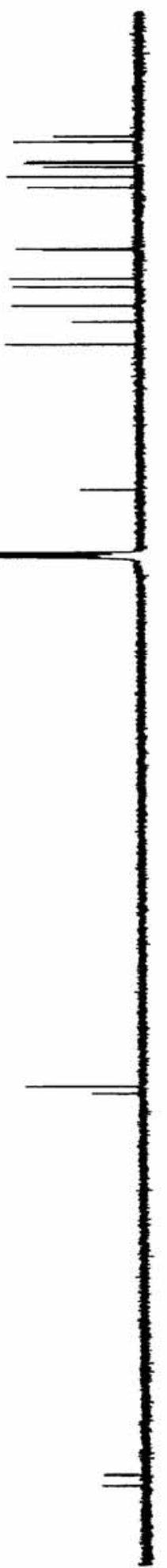

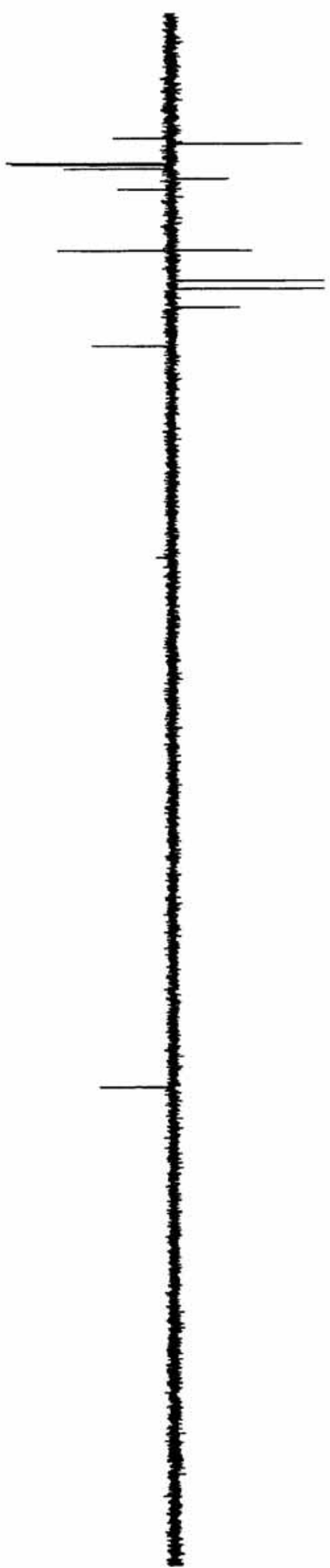

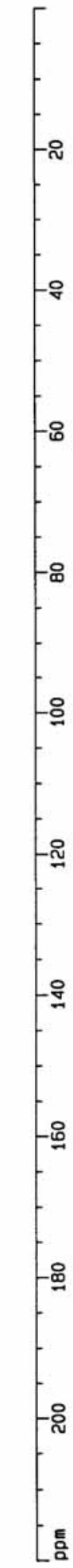

